REVISTA DE DERECHO UNED, NÚM. 11, 2012

\title{
LA RESPONSABILIDAD DE LOS CARGOS PÚBLICOS POR SU MALA GESTIÓN
}

\author{
RESPONSIBILITY OF THE PUBLIC CHARGES \\ FOR HIS BAD ADMINISTRATION
}

\begin{abstract}
Emma Arbeloa
Abogada del ICAM, Máster en Derechos Fundamentales por la UNED
\end{abstract}

Resumen: El artículo analiza la crisis actual y su origen en la mala administración pública, derivada de la corrupción y la inmunidad de la que disfrutaban los cargos públicos hasta ahora. La nueva Ley de Transparencia parece que quiere cambiar la situación sancionando de forma más rotunda, la corrupción e incompetencia de los cargos públicos.

Palabras clave: Cargos Públicos, Corrupción, Mala Administración Pública, Responsabilidad.

Abstract: The article analyzes the actual crisis and its origin in bad Public Administration, derived from the corruption and the immunity that public offices enjoyed until now. The new Law on Transparency seems to want to change the situation with strong sanctions for corruption and incompetence in public office.

Keywords: Public office, Corruption, Bad Public Administration, Responsibility.

Recepción original: 10/07/2012

Aceptación original: 12/07/2012

Es de todos es conocido que España no pasa por el mejor momento de su historia en el terreno de lo económico y financiero, si bien es cierto que la actual crisis tiene aspectos que se repiten en 
otros países del mundo y que fundamentalmente tienen su origen en China y EEUU.

En 1994 China devaluó el yuán en un 40\% y, al mismo tiempo, para lograr el alza de las exportaciones, así como evitar desequilibrios económicos, emitió sumas importantes de dinero.

Por su parte, EEUU, a raíz del estallido de la burbuja tecnológica en 2001, redujo drásticamente la tasa de interés que, como afirma PEDRO ASPE, unido «al aumento de liquidez derivada de una mayor disponibilidad de recursos provenientes de la economía china y de los productores petroleros de Medio Oriente», ${ }^{1}$ condujo a una política bancaria mucho más flexible a la hora de otorgar hipotecas inmobiliarias a familias con dificultades para pagar: los famosos "créditos subprime» o hipotecas basura, que los bancos, a su vez, comercializaron como bonos hipotecarios a bancos de todo el mundo (los «mortgage backed security: MBS» o el fondo estratégico de crédito estructurado de alta gama o el fondo de apalancamiento de crédito estructurado de alta gama que, en definitiva, no eran otra cosa que fondos opacos y muy tóxicos). Pero cuando la burbuja inmobiliaria estalló en 2007, no sólo bajó el precio de las viviendas, sino también de los bonos hipotecarios llevando a la quiebra a dos de la mayores bancos de inversión de EEUU: Bear Stearns y Lehman Brothers y al desplome de las bolsas en el mundo entero.

La referida crisis económica y financiera, ha sido provocada, en gran medida, por la falta de transparencia, que ha llevado a la pérdida de confianza por parte de los inversores, y en consecuencia, a la contracción del crédito a las empresas.

No obstante, si hemos de reclamar responsables de la «mala Administración Pública» en nuestro propio país, nuestra mirada debe dirigirse a los cargos públicos, entre los que incluyo tanto a aquellos representantes elegidos por sufragio universal en elecciones democráticas, como a los sectores del alto funcionariado y altos cargosnombrados en general por libre designación.

El número de cargos públicos representativos en España, asciende a 71.668 según las últimas elecciones generales: 350 diputados y 208 senadores; 1.268 diputados autonómicos en las 17 comunidades, Ceuta y Melilla; 1.040 diputados provinciales, 157 consejeros insulares y 13 consejeros del Valle de Arán; 68.578 con-

${ }^{1}$ ASPE, P.: «Los orígenes de la crisis», en la web CNNExpansión

http://www.cnnexpansion.com/economia/2009/02/06/los-origenes-de-la-crisis [consulta: 1 agosto 2012] 
cejales en los 8.116 Ayuntamientos; y 54 diputados en el Parlamento Europeo.

El anteproyecto aprobado por el Consejo de Ministros para cambiar la ley electoral pretende reducir en un 30\% el número de concejales en España, medida que no sería efectiva hasta el año 2015 tras las próximas elecciones.

El número de funcionarios, en julio de 2011, llegaba a 2.690.099², repartidos de la siguiente manera:

Administración Pública Estatal ...................... 592.531

Administraciones de las CCAA ..................... 1.347.835

Administración Local ..................................... 646.627

Universidades................................................ 103.106

De los mismos, un porcentaje significativo son elegidos de manera discrecional.

Respecto a los expresados datos es de interés señalar que, el número de altos cargos resulta tarea harto difícil de precisar con datos oficiales, tal y como admite el Ministerio de Hacienda y Administraciones Públicas, que en la Ley 5/2006, de 10 de abril, intentaba especificarlos en lo que se refiere a la Administración General del Estado en ese momento.

Cargos públicos que como es todos sabido, en algunos casos se han revelado como corruptos y que han contribuido a que el grado de percepción de la corrupción en España, según el último informe de Transparencia Internacional, se sitúe en el puesto número $34^{3}$ frente al puesto 23, que llegó a obtener en 2004, siendo estas cifras, casi con seguridad, menores de las que existan en la realidad.

En cualquier caso, es en el ámbito político donde la percepción de la corrupción se acentúa, lo que no es de extrañar si se consideran algunos de los últimos escándalos, como el número a todas luces excesivo de funcionarios, asesores y altos cargos nombrados a dedo, práctica de la que no se escapa ningún gobierno.

Así, resulta particularmente llamativo el caso de la Junta de Andalucía, gobernada por el partido socialista (:PSOE), y donde más casos de

${ }^{2}$ Boletín Estadístico del Personal al Servicio de las Administraciones Públicas. Registro Central de Personal, julio de 2011, pág. 18. Disponible en:

http://www.seap.minhap.gob.es/dms/es/publicaciones/centro_de_publicaciones_de_la_sgt/Periodicas/parrafo/Boletin_Estadis_Personal/Bol_estad_pers-juli11INTERNET.pdf [consulta: 20 marzo 2012]

${ }^{3}$ TRANSPARENCIA INTERNACIONAL: Índice de percepción de la corrupción, 2011. 
corrupción se han denunciado. Según fuentes del SAFJA ${ }^{4}$, a través de agencias creadas a raíz de la Ley 1/2001, de 17 de febrero, de reorganización del sector público de Andalucía ${ }^{5}$, conocida como «ley del enchufismo", se han suscrito en los últimos seis meses contratos con personas externas a la Administración General de la Junta de Andalucía para gestionar servicios públicos, por un monte de 42 millones de euros. Servicios que, de ser gestionados por funcionarios públicos supondría un mayor ahorro para las agotadas arcas andaluzas y del Estado.

Si bien es cierto que, la mencionada Ley que ha sido recurrida por el Partido Popular (:PP) en el Tribunal Constitucional (recurso de inconstitucionalidad $n .^{\circ} 2733-2011$ ), pero mientras tanto, estas personas siguen en sus puestos y lo que es peor, se sigue contratándolas, menospreciando totalmente «la buena fe legislativa». ${ }^{6}$

Igualmente, resultan escandalosas las subvenciones y ventajas fiscales a las grandes multinacionales, que no les obligan a mantener la plantilla de trabajadores. Subvenciones a fundaciones con extraños objetivos, a sindicatos y partidos políticos. Subvenciones para asegurarse la fidelidad electoral, entre ellas el AESPA-antiguo PERsubsidio agrario de 6 meses, que exige 20 días trabajados y del que se benefician 260.000 jornaleros.

De otra parte, tampoco se puede echar en saco roto, las sucesivas ayudas a la banca para asegurar la estabilidad del sector. Ya en el 2009 se procedió a un importante rescate, lo que no evitó que el ejecutivo, al amparo del RD-L 2/2012 de 3 de febrero, de saneamiento del sector financiero ${ }^{7}$, se aprobara nuevas provisiones y, según el informe del Banco de España de 25 de junio de $2012^{8}$, se formalizara la solicitud de ayuda financiera a las instituciones europeas con el fin de recapitalizar las entidades bancarias más débiles, acordando

${ }^{4}$ SAFJA deja al descubierto la "tercera Administración paralela": 26 de marzo de 2012, https://www.sindicatofuncionariosja.org/index.php/noticias/actualidad/3834safja-deja-al-descubierto la-tercera-administracion-paralela. [consulta: 14 abril 2012]

${ }^{5}$ BOE n. ${ }^{\circ}$ 53, de 3 de marzo de 2011, pág. 24188.

http://www.boe.es/boe/dias/2011/03/03/pdfs/BOE-A-2011-4039.pdf [consulta: 20 marzo 2012 ]

${ }^{6}$ Los italianos MARIO DOGLIANI e ILENIA MASSA PINTO definen muy bien la buena fe legislativa como: «el principio de la esencia de la esencia nacional de la representación, en virtud del cual, el carácter mayoritario y, por lo tanto. "de parte", de la legislación no debe traducirse en la adopción de leyes dictadas para la tutela de meros intereses privados de quien, pro tempere, es dominus de la potestad legislativa»: La crisis constitucional italiana en la fase actual, Revista de la UNED Teoría y Realidad, n. ${ }^{\circ}$ 16, 2005, pág. 167.

${ }^{7}$ BOE n. ${ }^{\circ}$ 30, de 4 de febrero de 2012, pág. 9889.

${ }^{8}$ BANCO DE ESPAÑA: "Informe trimestral de la economía española», Boletín económico, julio-agosto 2012, pág. 16. 
el Eurogrupo la concesión por un importe máximo de $100 \mathrm{~mm}$ de euros. Y aunque la ayuda será para los bancos, al pasar antes por el FROB (Fondo de Reestructuración Ordenada Bancaria) ${ }^{9}$, los 100.000 millones computarán como deuda pública y los intereses a pagar aumentarán el déficit del Estado. Es decir, los bancos, que durante años han alcanzado cuantiosos beneficios con prácticas no siempre éticas (basta recordar el «affaire» de las preferentes ${ }^{10}$ ), ahora en momentos de crisis solicitan de los españoles su solidaridad y el rescate financiero público.

Españoles (más de 350.000 según fuentes del periódico estadounidense The Washington Post ${ }^{11}$ ) que no sólo han perdido sus hogares en los últimos años, sino que mantienen con los bancos una deuda, que puede suponer el embargo de parte de sus salarios, o en el peor de los casos de parte de sus pensiones. Porque no olvidemos que en España, a diferencia de muchos países de nuestro entorno ${ }^{12}$, «del cumplimiento de las obligaciones responde el deudor con todos sus bienes, presentes y futuros» (art.1011 Código Civil:CC); y «la herencia comprende todos los bienes, derechos y obligaciones de una persona que no se extingan por su muerte» (art. $659 \mathrm{CC}$ ).

${ }^{9}$ FROB es una entidad de Derecho Público con personalidad jurídica propia, que tiene por objeto gestionar los procesos de reestructuración y resolución de las entidades de crédito.

${ }^{10}$ Producto muy complejo que la banca vendió a particulares, muchas veces sin su conocimiento e incluso sin su consentimiento, como si fueran depósitos.

${ }^{11}$ ASSOCIATED PRESS: «Major Spanish banks halt evictions of neediest for 2 years after many left homeless», en el Periódico The Washington Post, Washington, 12 de noviembre de 2012.

${ }^{12}$ Así, en Alemania rige la Ley de la Insolvencia («Insolvenzordnung») de 4 de octubre de 1994, que prevé en caso de fracaso de acuerdo entre deudor y acreedores, un procedimiento de insolvencia, en el que se procede a la liquidación del patrimonio del deudor entregando el precio a un fiduciario que paga a los acreedores, y si las deudas no se satisfacen íntegramente puede establecerse un plazo de 7 años para pagar, pero si las deudas se satisfacen totalmente, se produce la liberación de la deuda, en la parte todavía no satisfecha: MORENA SANZ, G. en Curso del ICAM sobre Las causas de oposición en la ejecución hipotecaria y la intervención del abogado en el concurso de acreedores, Madrid, 16 de septiembre de 2008.

En el Reino Unido, rige por su parte la Ley de Quiebras de 1986 y sus enmiendas («Bankruptcy Act»), por la que se nombra un administrador judicial que tiene 3 años para llegar a un acuerdo de pago o de venta de la casa, si bien se desestima cualquier orden de embargo o venta que no supere las $1000 £$. Y si el administrador en dicho plazo no toma ninguna acción la propiedad retorna a su dueño: THE INSOLVENCY SERVICE: Bankrupt's home http://www.bis.gov.uk/insolvency/personal-insolvency/ bankrupts-home\#lose-home [consulta: 21 mayo 2012]

Mientras que en EEUU el insolvente hipotecario o entrega voluntariamente las llaves de su caso o se ejecuta la subasta judicial de la vivienda para satisfacer el crédito, pero en caso de ser insuficiente, no queda obligado al pago del resto de la deuda. 
De modo que, ante el impago de la hipoteca, el acreedor para exigir el pago de la deuda podrá ejercitar la acción hipotecaria (art. 681 Ley $1 / 2000$, de 7 de enero, de Enjuiciamiento Civil: LEC ${ }^{13}$ ), y «si, subastados los bienes hipotecados (...), su producto fuera insuficiente para cubrir el crédito [principal, intereses y costas], el ejecutante podrá pedir el despacho de la ejecución por la cantidad que falte, y contra quienes proceda, y la ejecución proseguirá con arreglo a las normas ordinarias aplicables a toda ejecución» (art. 579 LEC).

No parece muy justo, y así lo ha reconocido un dictamen de la abogada general del Tribunal de Justicia de la Unión Europea (:TUE), Juliane Kokoel, ${ }^{14}$ al afirmar que ley española relativa a los desahucios viola la Directiva 93/13/ CEE del Consejo, de 5 de abril de 1993, sobre las cláusulas abusivas en los contratos celebrados con consumidores ${ }^{15}$, al no permitir paralizar el desahucio invocando una cláusula abusiva del contrato de préstamo hipotecario establecido por el banco. Cuestión, que debe solucionarse en otro juicio una vez que ya se ha ejecutado la expulsión. «El consumidor [español] solo está protegido jurídicamente a posteriori por la indemnización de daños y perjuicios y debe (...), soportar la pérdida de su vivienda». La Directiva 93/13 exige, antes bien, que « el órgano jurisdiccional que conoce del procedimiento declarativo [...disponga] de la posibilidad de suspender (de forma provisional) el procedimiento ejecutivo, con objeto de detener la ejecución forzosa, hasta que se haya comprobado el carácter abusivo de una cláusula contractual, de modo que se impida que el procedimiento ejecutivo cree una situación perjudicial para el consumidor que posteriormente sea de muy difícil o imposible reparación».

Aunque parece ser que nuestros cargos públicos solo han reaccionado, cuando la prensa internacional se hace eco de las trágicas consecuencias que conlleva la presente legislación. Así, los dos grandes partidos: PP y PSOE, negocian actualmente la aprobación de un real decreto para dar una solución urgente al problema de los desahu-

${ }^{13} \mathrm{BOE} \mathrm{n.}^{\circ} 7$, de 8 de enero de 2000.

Texto consolidado disponible en: http://www.boe.es/buscar/act.php?id=BOEA-2000-323. [consulta: 14 noviembre 2012]

${ }^{14}$ Asunto C-415/11. Mohamed Aziz contra Caixa d'Estalvis de Catalunya, Tarragona i Manresa (Catalunyacaixa). (Petición de decisión prejudicial planteada por el Juzgado de lo Mercantil n. ${ }^{\circ} 3$ de Barcelona).

${ }^{15}$ Diario Oficial de las Comunidades Europeas $n .{ }^{\circ}$ L 095, de 21 de abril de 1993, pág. $0029-0034$.

Texto disponible en: http://eurlex.europa.eu/LexUriServ/LexUriServ.do?uri=CEL EX:31993L0013:ES:HTML. [consulta: 14 noviembre 2012] 
cios, que prevería el aplazamiento de los desahucios de colectivos especialmente vulnerables durante dos años.

Por lo que se refiere a la corrupción vinculada a la corrupción urbanística, en palabras de MANUEL VILLORIA MENDIETA «parece claro que la corrupción en España está mayoritariamente vinculada a la acción de los actores políticos [y] se da sobre todo en el ámbito urbanístico, en la Administración Local y, en gran medida, está conectada con la financiación partidista» ${ }^{16}$.

Por otro lado, es obligado explicitar al tratar de la corrupción en el ámbito funcionarial que, como se recoge por VILLORIA MENDIETA, con base en datos facilitados por Transparencia Internacional, "la intervención funcionarial [en la corrupción] es muy minoritaria [...lo que] no obsta para que la percepción de corrupción en la Administración sea mucho más elevada de lo que los datos objetivos reflejan ${ }^{17}$.

Tampoco se puede dejar de mencionar que, entre los altos cargos públicos son ya un número muy elevado los que han saltado a la palestra pública vinculados a la corrupción, a pesar de que en no pocos casos se les haya exonerado por sus pares de las formas sutiles y poco claras y a la pregunta de ¿cuántos cargos electos, funcionarios o altos cargos públicos han sido imputados y condenados realmente?, entiendo que hasta ahora no es un número tan elevado como los medios de comunicación y el sentir popular dan a entender.

Inmunidad e impunidad no pueden achacarse a falta de previsión legislativa. El Código Penal (:CP $)^{18}$ prevé los delitos de corrupción, como el cohecho, la prevaricación, el tráfico de influencias, la revelación de secretos, el manejo de información privilegiada y la malversación de fondos. Pero también otras leyes importantes regulan la responsabilidad de los cargos públicos. Así, la Ley 36/2006, de 29 de noviembre, de Medidas para la Prevención del Fraude Fiscal ${ }^{19}$, obliga a consignar el NIF y los medios de pago empleados en las escrituras notariales relativas a actos y contratos sobre bienes inmuebles, sin cuyo requisito no es posible la inscripción en el Registro de la Pro-

${ }^{16}$ VILLORIA MENDIETA, M.: «La ética pública y los códigos de conducta administrativa vs. Corrupción y escándalos políticos», en El derecho a una buena administración y la ética pública, C. M. ${ }^{a}$ Ávila Rodríguez y F. Gutiérrez Rodríguez (Coordinadores), edit. Tirant, Valencia, 2011, pág. 185.

${ }^{17}$ VILLORIA MENDIETA y F. JIMÉNEZ, M.: «La corrupción en España (20042010): datos, percepción y efectos», Reis 138, abril-junio 2012, págs. 118 y 120.

${ }^{18}$ BOE n. ${ }^{\circ} 281$, de 24 de noviembre de 1995, pág. 33987.

Texto consolidado disponible en: http://www.boe.es/buscar/act.php?id=BOEA-1995-25444. [consulta: 14 noviembre 2012]

19 BOE n. ${ }^{\circ} 286$, de 30 de noviembre de 2006, pág. 42087. 
piedad, así como la referencia catastral en los contratos de suministro de energía eléctrica y de arrendamiento o en los de cesión de uso de bienes inmuebles y, lo que es de gran relevancia, adopta normas contra los paraísos fiscales.

En igual sentido, el conjunto de nuestro ordenamiento jurídico contempla una autentica red descoordinada de medidas y supuestos para evitar prácticas irregulares, así como la corrupción en todos los ámbitos, entre las que baste por señalar a título indicativo:

- la Ley 10/2010, de 28 de abril, sobre la Prevención del blanqueo de capitales y financiación del terrorismo ${ }^{20}$, prevé el control del patrimonio y los fondos de personas con responsabilidad pública actual o pasada, sus familiares o allegados;

- la Ley Orgánica 2/1982, de 12 mayo, del Tribunal de Cuentas ${ }^{21}$ en el art. 34, fija el deber de rendición de las cuentas públicas por las normas contables, presupuestarias y financieras;

- la Ley 5/2006, de 10 de abril, de regulación de los conflictos de intereses de los miembros del Gobierno y de los Altos Cargos de la Administración General del Estado ${ }^{22}$, regula incompatibilidades, limitaciones patrimoniales y actividades post-empleo de los altos cargos públicos;

- el Código de Buen Gobierno de los miembros del Gobierno y de los altos cargos de la Administración General del Estado, aprobado el 18 de febrero de $2005^{23}$, dispone que estos asuman la responsabilidad en todo momento de las decisiones y actuaciones propias y de los organismos que dirigen, sin perjuicio de otras que fueran exigibles legalmente;

— el art. 18 del Reglamento del Congreso de Diputados ${ }^{24}$ estipula que «los Diputados estarán obligados a formular declaración de sus bienes patrimoniales en los términos previstos en la Ley Orgánica del Régimen electoral General»;

— la Ley 53/1984, de 26 de diciembre, de Incompatibilidades del Personal al Servicio de las Administraciones Públicas ${ }^{25}$ «exige de los servidores públicos un esfuerzo testimonial de ejempla-

\footnotetext{
${ }^{20}$ BOE n. ${ }^{\circ} 103$, de 29 de abril de 2010, pág.37458.

${ }^{21}$ BOE n. ${ }^{\circ} 121$ de 21 de mayo de 1982, páginas 13290 a 13294.

${ }^{22}$ BOE n. ${ }^{\circ} 86$, de 11 de abril de 2006, pág.13954.

${ }^{23}$ BOE n. ${ }^{\circ}$ 56, de 7 de marzo de 2005, págs. 7953 a 7955.

${ }^{24} \mathrm{BOE} \mathrm{n.}{ }^{\circ} 55$ de 05/03/1982.

${ }^{25} \mathrm{BOE} \mathrm{n.}{ }^{\circ} 4$, de 4 de enero de 1985, págs. 165 a 168.
} 
ridad ante los ciudadano», regulando las excepciones al mandato de dedicación exclusiva a un solo puesto de trabajo en la Administración Pública;

- la Ley del Suelo de mayo de $2007^{26}$, introduce incompatibilidades y controles respecto a los representantes locales con responsabilidades ejecutivas, que conllevan la prohibición de no desempeñar sus servicios en empresas o sociedades privadas relacionadas directamente con las competencias del cargo desempeñado, durante los dos años siguientes a la finalización de su mandato.

A pesar de esa red tan amplia como dispersa de normas contra la corrupción, con el nuevo proyecto de Ley de Transparencia, Acceso a la Información Pública y Buen Gobierno ${ }^{27}$ aplicable a los miembros del Gobierno, a los Secretarios de Estado y al resto de los altos cargos de la Administración General del Estado y de las entidades del sector público estatal, de derecho público o privado, vinculadas o dependientes de aquella (art. 22), se pretende reafirmar el control y la transparencia de la Administración Pública. Así, distingue entre: infracciones en materia de conflicto de intereses (art. 24); de gestión económica-presupuestaria, como el despilfarro del dinero público, el ocultamiento de facturas, o las relativas al incumplimiento de la Ley Orgánica 2/2012, de 27 de abril, de Estabilidad Presupuestaria y Sostenibilidad Financiera ${ }^{28}$-como el superar el límite de déficit público, la utilización de compromisos de gastos sin tener crédito para hacerlo o en contra de la legislación aplicable, la ausencia de justificación de la inversión de los fondos con arreglo a la Ley de Subvenciones, el incumplimiento deliberado del nivel de deuda pública y no formular los planes económico financieros en los supuestos que figura en la Ley de Estabilidad- (art. 25); y en el ámbito disciplinario, como la no aportación de documentación requerida por los tribunales o los órganos de fiscalización contable (art. 26). Siendo el plazo de prescripción de las infracciones previstas, de cinco años para las infracciones muy graves, tres para las graves y uno para las leves (art. 29.1).

En el mencionado Proyecto de Ley de Transparencia, se prevé modificar el CP para tipificar como delito las infracciones más graves en la gestión de los recursos públicos, las sanciones compren-

${ }^{26}$ BOE n. ${ }^{\circ} 128$, de 23266, de 29 de mayo de 2007, pág. 23266.

${ }^{27}$ Texto aprobado en el Consejo de Ministros de 27 de julio de 2012

http://www.leydetransparencia.gob.es/anteproyecto/index.htm\#22 [consulta: 4 agosto 2012]

${ }^{28}$ BOE n. ${ }^{\circ} 103$, de 30 de abril de 2012, pág. 32653. 
den la destitución de los cargos públicos que ocupen (salvo que ya hubieran cesado en los mismos) y la no percepción de pensiones indemnizatorias; la inhabilitación por un periodo de entre cinco a diez años; la obligación de restituir las cantidades percibidas; y la indemnización a la Hacienda estatal o, en su caso, a la respectiva entidad los daños y perjuicios que sean consecuencia de aquellos, con independencia de la responsabilidad penal o disciplinaria que les pueda corresponder (art. 27). Las sanciones que prescribirían a los cinco años si son impuestas por infracciones muy graves, a los dos años tratándose de infracciones graves y al año por la comisión de infracciones leves (art. 29.2).

Entonces ¿por qué si los delitos relativos a la corrupción han estado regulados no se ha perseguido de forma más eficaz a los corruptos? Varias pueden ser las causas, aunque ante el panorama descrito, viene como anillo al dedo recordar en este momento al historiador romano TÁCITO, quien dijo que «plurimae leges, pessima República», esto es, cuando más corrupto el Estado más numerosas son las leyes.

En primer lugar, una de las causas de la falta de sincera persecución de la corrupción ha podido estar en la escasez de medios materiales y de personal del poder judicial para poder cumplir con su labor, que tampoco cuenta con los estímulos apropiados, ni con el reciclaje formativo necesario para sus ejercer competencias. Como apunta el informe La Justicia Dato a Dato $2010^{29}$ del CGPJ, el plazo medio para resolver asuntos en primera instancia es de unos cuatro meses; en segunda instancia de cinco meses y en el Supremo más de un año y medio. Retrasos que conllevan, más veces de las que desearíamos, la no condena de cargos públicos porque los delitos han prescrito.

En consecuencia, sería necesario aumentar el número de funcionarios judiciales. Un incremento que en tiempos de crisis y recortes presupuestarios puede parecer imposible, pero que en mi opinión es más que necesario, pues sin justicia a tiempo no hay justicia y sin justicia, no hay seguridad jurídica ni progreso.

La Ley 18/2011, de 5 de julio, reguladora del uso de las tecnologías de la información y la comunicación en la Administración de Justicia $^{30}$ supone por otro lado, un avance importante para lograr una justicia más rápida y próxima a los ciudadanos. Uso de nuevas tecnologías que debería extenderse a todos los ámbitos administra-

${ }^{29}$ CGPJ.: La Justicia Dato a Dato 2010, pág. 107.

${ }^{30}$ BOE n. ${ }^{\circ} 160$, de 6 de julio de 2011, págs. 71320 a 71348. 
tivos, porque una administración electrónica puede resultar más transparente y difícil de corromper.

Personalmente entiendo que el futuro está en la e-democracia. Internet, que ya es una realidad presente en una mayoría de hogares, y que permite a cualquiera -con unos mínimos conocimientos- hacer llegar una información o denuncia de forma rápida a todo el mundo.

Aunque no hay que olvidar, que existe una amplia creencia entre la ciudadanía de que la corrupción es un trámite más por el que hay que pasar en las relaciones con la Administración Pública.

En concreto, según la encuesta Eurobarómetro de 2012 publicada por la Comisión Europea, «el 70\% de los europeos cree que la corrupción es inevitable y que siempre ha existido» ${ }^{31}$, de modo que son muchos ciudadanos los no se molestan en denunciar las posibles conductas corruptas, cuando de acuerdo con Fernandez Asenjo, «la denuncia y la represión de la defraudación de los intereses públicos corresponden en estos momentos prioritariamente a la Sociedad Civil y a los Tribunales de la jurisdicción penal con la colaboración de la Administración inspectora ${ }^{32}$.

En efecto, el fomento de la participación ciudadana se presenta como una medida esencial para la lucha contra la corrupción. Y es cierto que ha faltado concienciación al respecto: Mirando atrás, podemos ver, que en tiempos de bonanza, interesarse por la política y los partidos, no era algo prioritario para los ciudadanos, porque «las cosas» parecían funcionar. Sin embargo, cuando todo va mal, los ciudadanos tienden a buscar culpables y a identificarlos, normalmente, con los partidos, ya estén en el poder -porque no han sabido gobernar según los principios de una buena administración pública-, ya estén en la oposición -porque no han sabido defender a sus votantes de las malas políticas del gobierno-. De ahí, que se reclame que se escuche «la voz del pueblo».

Pero sobre todo, parece que la falta de una real persecución de la corrupción hasta ahora, puede vincularse a una ausencia de voluntad de aplicar la ley, así como el corporativismo político y funcionarial, como en otras profesiones existe y, en suma, el hoy por ti y mañana por mí, ha estado o está todavía muy presente.

${ }^{31}$ COMISIÓN EUROPEA: Eurobarómetro ¿Aumenta la corrupción?, Bruselas, 15 de febrero de 2012.

${ }^{32}$ FERNÁNDEZ ASENJO, J.A.: El control de las Administraciones Públicas y la lucha contra la corrupción, edit. Thomson Reuters, Navarra, 2011, pág.571.

(C) UNED. Revista de Derecho UNED, núm. 11, 2012 
Sin ir muy lejos en el tiempo, el Presidente RAJOY, declaraba en el debate de investidura que «en la política no existe la herencia a beneficio de inventario (...) No hay ninguna voluntad de mirar atrás ni de pedir a nadie responsabilidades, que ya han sido sustanciadas por las urnas hace un mes ${ }^{33}$. Postura que muchos consideraran generosa y de «fair play» democrática, pero que, ¿no supone tal renuncia una abdicación de las propias responsabilidades?

La «mala Administración» resulta contraria al derecho fundamental que todo ciudadano tiene a la buena Administración, como reconoce el art. 41 de la Carta de los Derechos Fundamentales, aunque como derecho de tercera generación ${ }^{34}$ tenga un reconocimiento desigual por los Estados y no se recoja todavía en todos los ordenamientos jurídicos. La «mala Administración» es contraria a la misma dignidad de los administrados, en tanto que viola los principios de igualdad, seguridad jurídica y legalidad, derechos fundamentales para mantener la paz social.

Si la «mala administración» de los cargos públicos no es juzgada por nuestros tribunales o lo es, pero de forma arbitraria, la ciudadanía seguirá perdiendo la confianza, además de en sus cargos públicos, en la Justicia -que debe ser ciega y tratar a todos por igual-, como en el poder coercitivo de las leyes y la separación de poderes, que constituyen la base de las libertades públicas y la democracia.

Pero eso no es todo, esa política de no exigir responsabilidades a los cargos públicos ha perpetuado y propiciado la corrupción en España. Si un cargo público sabe que sus actos contrarios al derecho o a la ética y moral, no serán perseguidos y serán justificados, pocos se sustraerán a la tentación.

No es menos preocupante que, de no poner punto final a la corrupción y prácticas irregulares en todas las administraciones -una

${ }^{33}$ RAJOY, M: Diario de Sesiones del Congreso de Diputados n. ${ }^{\circ} 2$ de 19 de diciembre de 2011.

${ }^{34}$ Junto al derecho de la solidaridad, configuran un catálogo de derechos, todavía "in fieri», de las demandas actuales más acuciantes: al medio ambiente; al desarrollo sostenible; a la libre determinación de los pueblos; a la paz; a poder intervenir desde instituciones de carácter supranacional en los conflictos armados locales, imponiendo a la paz desde una fuerza legítima; la persecución sin fronteras de los dictadores; la limitación del derecho a la inmunidad diplomática para determinados delitos; el derecho a crear un tribunal internacional que actúe de oficio en los casos de genocidio y crímenes contra la humanidad; el derecho a un entorno multicultural, que supere el concepto de tolerancia, haciendo de la diferencia una ventaja y no un inconveniente; el derecho a la asistencia sanitaria,... 
minoría de cargos públicos, políticos, funcionarios y empleados públicos-, la mayoría de la función pública española, fiel cumplidora de sus obligaciones al servicio de los ciudadanos, seguirá perdiendo la credibilidad y la confianza de los administrados.

El transcurso del tiempo y la pasividad ante la corrupción y prácticas irregulares en las administraciones públicas, supone un peligroso retroceso en la implantación y consolidación de la democracia, así como un gran distanciamiento de cualquier proyecto de integración europea.

La actual crisis económica es también una crisis de valores -valores que una minoritaria parte de nuestra sociedad y nuestros cargos públicos parecen haber perdido u olvidado, si es que los tuvieron en alguna ocasión-, que perjudica gravemente al Estado de Derecho.

Citando a ANTONIO GARRIGUES WALKER ${ }^{35}$ "de esta crisis que tiene su origen en un proceso de corrupción financiera, aún básicamente impune (...) tenemos que aprender al menos tres cosas: que no se puede gastar más de lo que se tiene; que todas las burbujas explotan; y que sin ética no hay sostenibilidad, no hay futuro. La lucha decidida en favor de la transparencia y en contra de la corrupción -incluyendo la lucha, tantas veces anunciada en falso, contra el fraude fiscal- tiene que ser la clave de esta nueva época».

${ }^{35}$ GARRIGUES WALKER, A.: «Corrupción y transparencia», en el Periódico $A B C$, de 22 de enero de 2012. 